\title{
PREFACE
}

\section{Surviving and Thriving in the Schools}

\begin{abstract}
According to the most recent Omnibus Survey conducted by the American SpeechLanguage-Hearing Association, ${ }^{1}$ more than half of ASHA speech-language pathologist (SLP) members are employed in school settings. It seems fitting, therefore, to devote an issue of Seminars to particular issues of timely concern for professionals working in the school setting. I am grateful for the assistance of Dr. Kathleen Whitmire, Director of School Services, American Speech-Language-Hearing Association in compiling this provocative collection of articles for school-based Seminars readers. In assembling this collection, Dr. Whitmire and I have endeavored to address a broad variety of concerns, from those faced virtually every day (such as eligibility and caseload concerns) to those that are challenging perhaps in part because they are less common concerns (students needing help for low-incidence disorders in the school setting, such as dysphagia, or students requiring the use of interpreters). Topics such as the use of literacy teams or strategies for dealing with language problems in the upper grades will no doubt be of value to large numbers of readers; by far, the largest proportion of caseload for school-based SLPs appears to be in the areas of learning disabilities, reading and writing disorders, and specific language impairment. ${ }^{1}$ However, a substantial number of school-based SLPs see children with dysphagia, as Homer notes, and roughly half of respondents reported a likely need to be involved in training interpreters and translators
\end{abstract}

to work with them and their culturally/linguistically diverse $(\mathrm{C} / \mathrm{LD})$ students and families.

The contributed articles we present in this volume represent a mix of the ideal and pragmatic. Each of the contributors is "down in the trenches" and recognizes both the potential for excellent, visionary care of their students and the real challenges to the implementation of some programs, techniques or suggestions. Each also recognizes the unique abilities and limitations of specific schools and systems. It is our hope that readers will be able to take the experiences of contributing authors back to their own workplace as part of their ongoing efforts to improve the quality of care for children receiving their SLP services in the school setting.

Finally, although we do not normally carry letters to the editor, an article written in a recent issue of Seminars prompted reader A. Lynn Williams to offer a clarification on the use of multiple oppositions in phonological intervention. We are pleased to pass on Dr. Williams' response to Barlow and Gierut ${ }^{2}$ in this issue; the note may be found at the end of this volume.

\section{Nan Bernstein Ratner, Ed.D. Co-Editor in Chief ${ }^{1}$}

1. American Speech-Language-Hearing Association. 2002 Omnibus Survey. Caseload Report: SLP. Rockville, MD: Author; 2002

2. Barlow JA, Gierut JA. Minimal pair approaches to phonological remediation. Semin Speech Lang 2002; 23:57-67

Surviving and Thriving in the Schools; Editors in Chief, Nancy Helm-Estabrooks, Sc.D., and Nan Bernstein Ratner, Ed.D.; Guest Editor, Kathleen Whitmire, Ph.D., CCC-SLP. Seminars in Speech and Language, volume 24, number 3, 2003. ${ }^{1}$ Department of Hearing and Speech Sciences, University of Maryland, College Park, Maryland. Copyright (C) 2003 by Thieme Medical Publishers, Inc., 333 Seventh Avenue, New York, NY 10001, USA. Tel: +1(212) 584-4662. 07340478,p;2003,24;03,145,146,ftx,en;s100158a. 
